\title{
Carbon Nanotube Structure Vibration Based on Non-local Elasticity
}

\author{
Abdelkadir Belhadj", Abdelkrim Boukhalfa, Sid Ahmed Belalia \\ Computational Mechanics Laboratory, Department of Mechanical Engineering, \\ Faculty of Technology, University of Tlemcen, Algeria \\ * Corresponding author email: belhabdelkadir@gmail.com
}

Received: 14 November 2016 / Revised: 29 November 2016 / Accepted: 03 December 2016 / Published: 04 December 2016

\begin{abstract}
This manuscript investigates the bending vibration dynamic of a single walled carbon nanotube (SWCNT) based on the theory of non-local elasticity. Fundamental natural frequencies and mode shapes of the SWCNT are computed by using a semi-analytical procedure called differential quadrature method (DQM), which gives accurate results in reference with the exact solution.
\end{abstract}

Keywords: Carbon nanotube; vibration; non-local elasticity; frequency; Euler-Bernoulli; DQM

\section{Introduction}

Carbon Nanotubes (CNT's) are the main recent subject of research in nanotechnology, their discovery in 1991 by Lijima [1] has been considered as a big step for the scientific research and technology. Owing their remarkable properties, CNT's have offered exceptional properties for engineers and researchers that make them potentially useful for nanotechnology applications including: nano-electro-mechanical systems (NEMS) [2], Chemistry, optics, materials sciences, medicine and biology. The scientific investigations showed that CNT's are thermally good conductors even better than the purest diamond, electrically conductors as well as copper, and mechanically exceptional solid structures, which can rich a Young modulus of 1TPa, which mean one hundred times the tensile strength of steel [3]. The mechanical study of CNT's has been oriented to their dynamic behaviour using first molecular dynamic (MD) approach $[4,5]$, which requires much time and high performant computational resources. Then, the theoretical and mathematical approach had taken CNT's to other features by using the Continuum models based on the theory of nonlocal elasticity. Developed by Eringen [6], who demonstrated that the stress at a reference point is considered as a function of the strain at every point in the body, non-local elasticity is definitely a new theory that is different from the classical theory of elasticity. In 1977, Eringen [7] improves the relationship between the molecular dynamics (MD) and his theory of non-local elasticity, which are identical.

Many researches had been elaborated based on non-local elasticity investigated the vibrational wave propagation of CNT's [8-14]; in this paper the bending vibration of a pinned-pinned SWCNT has been investigated.

\section{Mathematical Modelling}

\subsection{Carbon Nanotubes Technology}

Carbon nanotubes are large molecules of the same size structured in chemical bonding of nanotubes shape; nanotubes naturally align themselves into "ropes" held together by Van der Waals forces. the diameter of a nanotube is on the order of a few nanometers, while they can be up to several millimeters in length. CNTs are categorized as single-walled nanotubes (SWNTs) as shows the Figure 1 and multi-walled nanotubes (MWNTs) depending upon the number of walls. Nanotubes are members of the fullerene structural family, which also includes the spherical bucky-balls, and the ends of a nanotube may be capped with a hemisphere 
of the Bucky-ball structure. Their name is derived from their long, hollow structure with the walls formed by one-atom-thick sheets of carbon, called graphene. The diameter of single-walled nanotubes (SWNTs) is most commonly close to $1 \mathrm{~nm}$, with a tube length that can be many thousands of times longer. In reference to the multi-walled carbon nanotubes (MWNT), SWNTs can shared exceptional electrical properties.

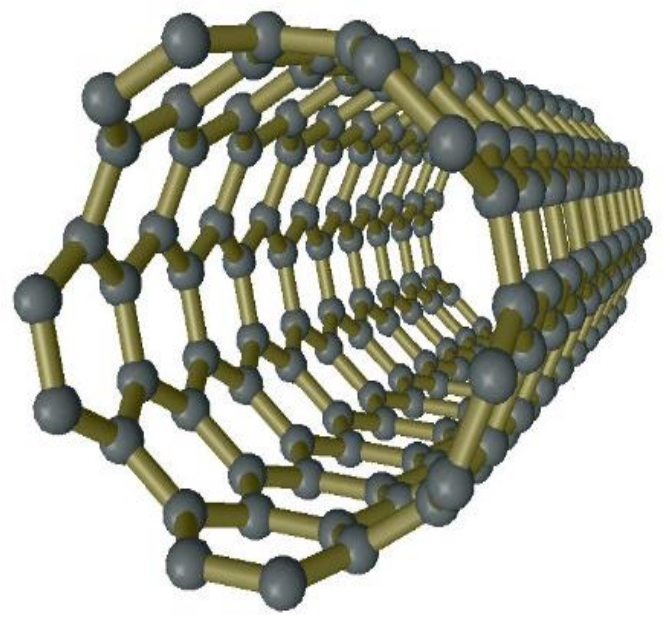

Figure 1: Molecular diagram of a Single walled carbon nanotube (SWCNT).

As in graphite, each atom joined to three neighbors, the tubes can therefore be considered as rolled-up graphene sheets, we can distinguish three different structures in which graphene can be rolled as tubes: zig-ag, armchair and chiral, Figure 2 showed the difference between each structures. Nanotubes can also be metallic or semiconducting, depending on their helicity indices, which opens up the interesting prospects of nanotube-based junctions and devices.

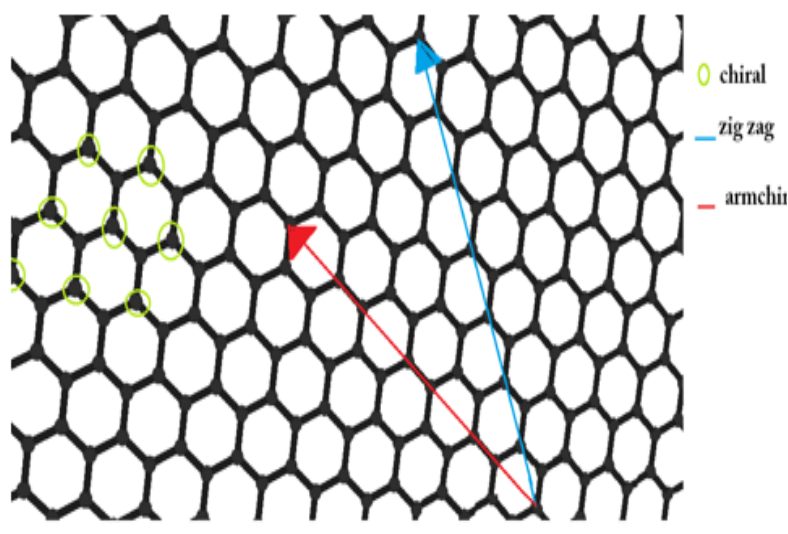

Figure 2: Structured bonding types of CNT's.

\subsection{Theory of Non-local Elasticity}

Nonlocal theory considers long-range interatomic interaction and yields results dependent on the size of a body, the stress at a reference point depends on the strain of other adjacent points of the body. In the following, the simplified form of the Eringen's nonlocal constitutive equation will be employed.

$\left(1-\left(e_{0} a\right)^{2} \nabla^{2}\right) \sigma^{n l}=\sigma^{l}$

where $\nabla^{2}$ is the Laplacian operator, $\left(e_{0} a\right)^{2}$ is the nonlocal parameter and $\sigma$ is the strain.

a - internal characteristic length, $\mathrm{e}_{0}$ - constant. nl- non-local, 1 - local

\section{Equation of Motion}

Based on Euler-Bernoulli beam, the equation of motion of a beam is [15]-

$\frac{\partial^{2}}{\partial^{2} x}\left(E I \frac{\partial^{2} w}{\partial x^{2}}\right)-\rho A \frac{\partial^{2} w}{\partial t^{2}}=0$

$E, I, A, \rho, w$ are, Young modulus, the moment of inertia, the cross section, the density and the transverse deflection respectively. When applying the non-local theory, the equation (3.1) becomes

$$
\begin{gathered}
\rho A\left[\frac{\partial^{2} w}{\partial t^{2}}-\left(e_{0} a\right)^{2} \nabla^{2} \frac{\partial^{2} w}{\partial t^{2}}\right]+E I \frac{\partial^{4} w}{\partial x^{4}}=0 \\
w(x, t)=W \cdot e^{i \omega t}
\end{gathered}
$$

Let define the dimensionless parameters as-

$$
\Omega^{2}=\frac{\rho A \omega^{2} L^{4}}{E I}, \mu=\frac{e_{0} a}{L}, \xi=\frac{x}{L} .
$$

The exact solution for the vibration of a simply supported beam is -

$$
\omega_{n}=\left(\frac{n \pi}{L}\right)^{2} \sqrt{\frac{E I}{\rho A}}
$$

The exact solution for the vibration of a simply supported nanobeam only is-

$\omega_{n}=\left(\frac{n \pi}{L}\right)^{2} \sqrt{\frac{E I}{\rho A \mu}}$

\section{Numerical Method}

The computation of the problem is based on the semi-analytical procedure: Differential Quadrature Method (DQM) [16], which is widely 
Belhadj et al., J. Mod. Mater.; Vol. 3, Issue 1, pp: 9-13, 2017

used to solve the vibration of nanostructures. It consists on the computing of the derivative of the function at a reference point known as Chebyshev-Lobatto-Gauss point-

$$
\xi_{i}=\frac{1}{2}\left(1-\cos \frac{(i-1) \pi}{N-1}\right) i=1,2 \ldots N
$$

The first derivative of the function to discretize is expressed as-

$A_{i, j}^{(1)}=\frac{P\left(\xi_{i}\right)}{\left(\xi_{i-} \xi_{j}\right) \cdot P\left(\xi_{j}\right)} i, j=1,2 \ldots N, i \neq j$

With $P\left(\xi_{i}\right)=\prod_{j=1}^{N}\left(\xi_{i-} \xi_{j}\right) \quad i \neq j$

$$
\begin{aligned}
& \text { and when } i=j, \quad A_{i, j}{ }^{(1)}=A_{i, i}{ }^{(1)} \\
& =\sum_{j=1}^{N} A_{i, k}{ }^{(1)} i=j=1,2 \ldots N, \quad i \neq k .
\end{aligned}
$$

The higher derivative of van be computed as following-

$$
\begin{aligned}
A_{i, j}{ }^{(r)}= & \sum_{i, j=1}^{N} A_{i, k}{ }^{(1)} A_{k, j}{ }^{(r-1)} \\
& \quad k=1,2 \ldots N ; r=1,2 \ldots m .
\end{aligned}
$$

The application of DQM gives the following governing equation [17]-

$$
\sum_{j=1}^{N} D_{i, j} W_{j}-\Omega^{2}\left(1-\mu^{2} \sum_{j=1}^{N} B_{i, j}\right) W_{j}=0
$$

\section{Results and Discussion}

A Matlab code [18] is used to compute the fundamental frequency parameters and its mode shapes for a simply supported boundary condition for the nanotube showed in Figure 3-

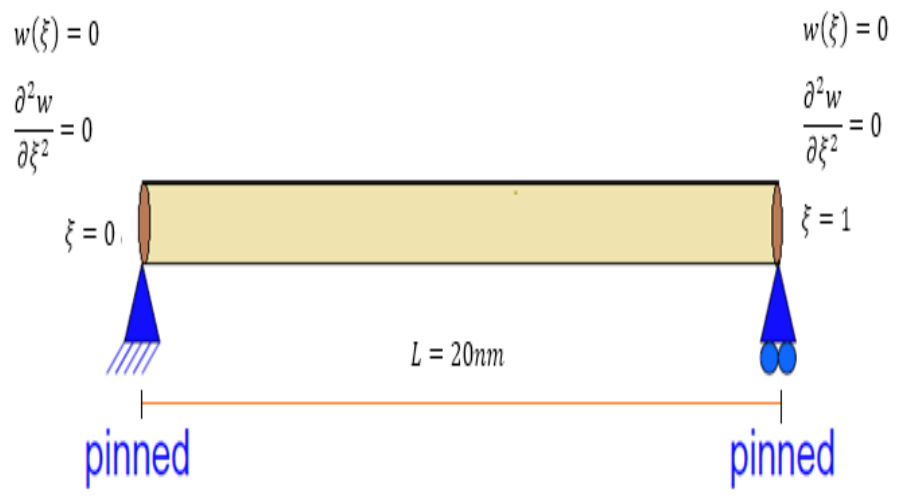

Figure 3: Simply supported boundary condition for SWCNT.
For the numerical computation, we took the following properties for the SWCNT-

$$
\begin{array}{ll}
m=3.25 \times 10^{-24} \mathrm{~kg} ; & D=1.356 \mathrm{~nm} ; \\
E I=358.66 \mathrm{~kg} \cdot \frac{\mathrm{nm}^{3}}{\mathrm{~s}^{2}}, & L=20 \mathrm{~nm} .
\end{array}
$$

The first three natural frequencies are computed in Table 1 for a non-local parameter ranging from 0.2 to 0.8 .

Table 1: First three natural frequencies for different values of non-local parameter.

\begin{tabular}{|c|c|c|c|c|c|c|c|}
\hline$\mu^{2}$ & 0.2 & 0.4 & 0.6 & 0.8 & local & Exact & $\begin{array}{c}\text { Error } \\
(\%)\end{array}$ \\
\hline $\begin{array}{c}1^{\text {st }} \\
\text { frequency } \\
(\mathrm{THz})\end{array}$ & 0.1733 & .2061 & 0.2281 & 0.2451 & 0.2595 & 0.2592 & $\begin{array}{c}11.57 \\
\times 10^{-4}\end{array}$ \\
\hline $\begin{array}{c}2^{\text {nd }} \\
\text { frequency } \\
(\mathrm{THz})\end{array}$ & 0.6933 & 0.8245 & 0.9125 & 0.9805 & 1.0372 & 1.0368 & $\begin{array}{c}3.85 \\
\times 10^{-4}\end{array}$ \\
\hline $\begin{array}{c}3^{\text {rd }} \\
\text { frequency } \\
(\mathrm{THz})\end{array}$ & 1.5600 & 1.8552 & 2.0531 & 2.2062 & 2.3333 & 2.3328 & 2.14 \\
& $\times 10^{-4}$ \\
\hline
\end{tabular}

For the local beam, it is remarkable that it gives a good agreement with the exact solutions; natural frequencies of the nanobeam converge with the increasing of the non-local parameter $\mu$, which improves its effect on the vibration dynamics at small-scale level. It is clearly noticeable that the natural frequencies of Carbon nanotubes are very important by reaching some Tera-hertz (THz), this is what make them offering exceptional optical and mechanical properties.

Figure 4 shows dependency of natural frequencies on the length of the SWCNT for $\mu^{2}=0.9$, the three natural frequencies converge to the same value in the end of the SWCNT, natural frequencies decrease with increasing the length of SWCNT. This vibrational bending behavior cannot be shown in other materials and structures, because natural frequencies can reach a Tera Hertz ( $\mathrm{THz}$ ) vibrational response, as shows the Figure 4. This is due to their exceptional Young's modulus $(\mathrm{E} \cong 1 \mathrm{TPa})$, their Poisson ratio $(0.06-0.55)$, and their tensile strength $75 \mathrm{GPa}$ for SWCNT's and < $60 \mathrm{GPa}$ for MWCNT's, which mean that CNT's are mechanically stronger than steel itself. The 
behaviour of nanotubes under large tensile strain strongly depends on their symmetry and diameter, their inter-atomic forces and external conditions. Figure 5 shows the mode shapes of the first three natural frequencies of SWCNT under pinned-pinned condition.

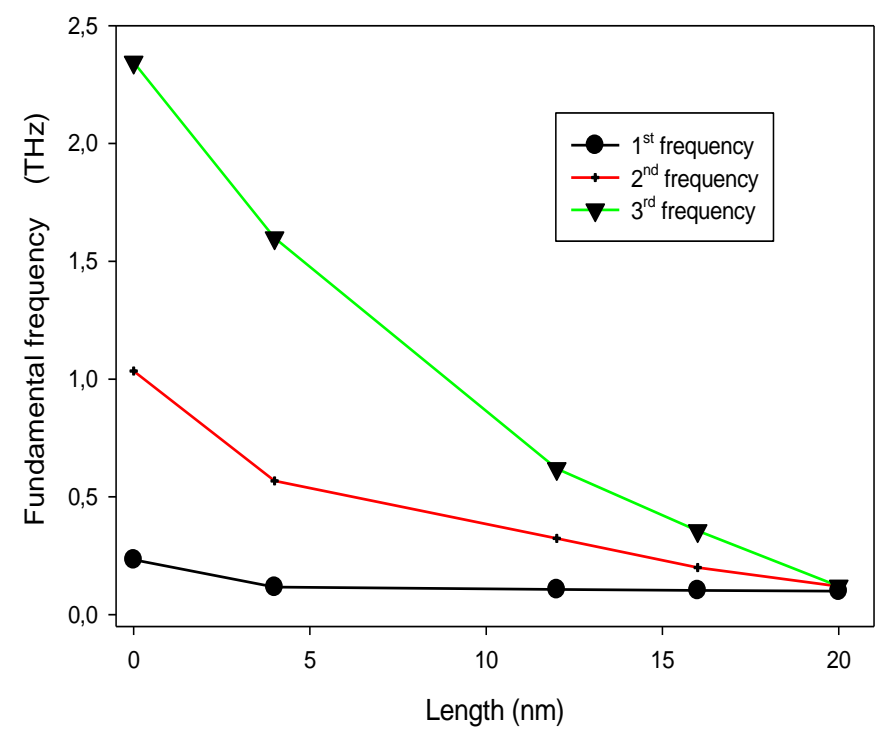

Figure 4: First fundamental frequencies versus the length of SWCNT for $\mu 2=0.9$.

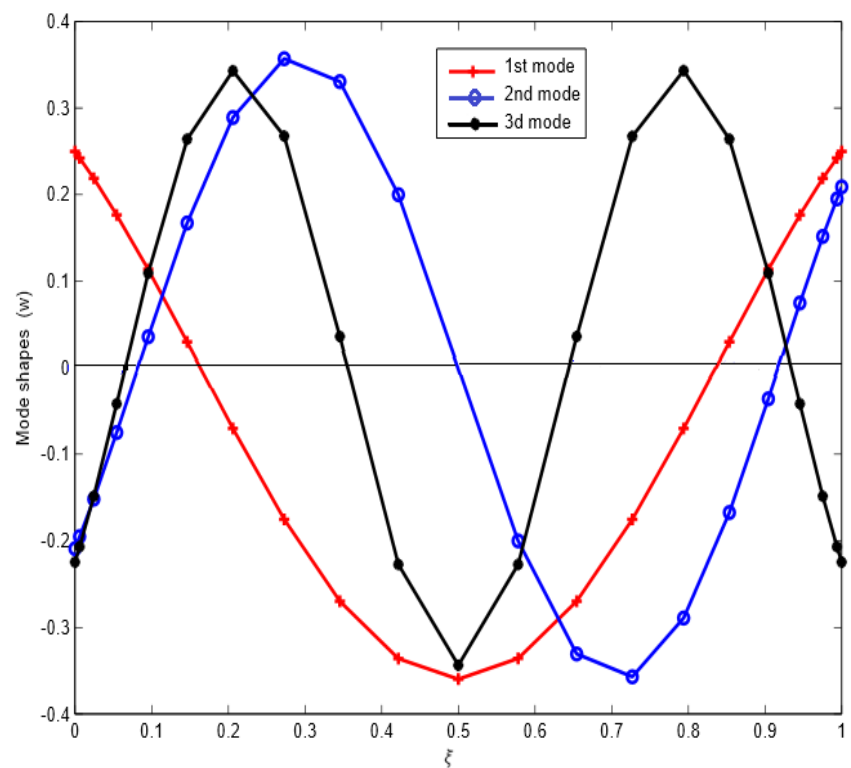

Figure 5: First three mode shapes corresponding to Eigen-frequencies.

\section{Conclusions}

In this paper, a computational structure dynamic (CSD) study is done investigating the bending vibration of a Single-walled carbon nanotube (SWCNT), the application of the non-local elasticity shows an accurate result. Natural frequencies of SWCNT given for different values of non-local parameter improve its effect on the bending vibration of simply supported CNT, local natural frequencies show good agreement with exact results. Length and diameter of CNT's have a significant influence on the optical and mechanical properties. Research in CNT's structure dynamic is very promising in reference to their exceptional properties and their unlimited applications in nanotechnology.

\section{How to Cite this Article:}

A. Belhadj, A. Boukhalfa, and S. Belalia, "Carbon Nanotube Structure Vibration Based on Non-local Elasticity", J. Mod. Mater., vol. 3, no. 1, pp. 9-13, Dec. 2016. doi:10.21467/jmm.3.1.9-13

\section{References}

[1] S. Iijima, "Helical microtubules of graphitic carbon" Nature, vol.354, pp. 56-58, 1991.

[2] S.N. Cha, J.E. Jang, Y. Choi, G.A.J. Amaratunga et al., "Fabrication of a nanoelectromechanical switch using a suspended carbon nanotube", Applied Physics Letters, vol. 86, no.8, p083105, 2005.

[3] J. Bernholc,D. Brenner, M. B. Nardelli, V. Meunier, C. Roland, "Mechanical and electrical properties of nanotubes" Annual Review of Materials Research, vol 32, no.1 pp347-375, 2002.

[4] F. ChenXin, C. YunFei, J. JiWei, "Molecular dynamics simulation of the test of single-walled carbon nanotubes under tensile loading", Science in China Series E: Technological Science, vol.50, no.1, pp7-17, 2007.

[5] K. P. Chong, "Nano science and engineering in solid mechanics". Acta Mechanica Solida Sinica, vol. 21, no2, pp 95-103, 2008.

[6] A. C. Eringen, "Nonlocal polar elastic continua". International Journal of Engineering and Science, vol.10, no.1, pp 1-16, 1972.

[7] A.C. Eringen, "Relation between non-local elasticity and lattice dynamics". Crystal lattice defects, vol. 7, pp. 51-57. 1977.

[8] Q. Wang, "Wave propagation in carbon nanotubes via nonlocal continuum mechanics", Journal of applied Physics. vol. 98, no 12, pp 124301, 2005.

[9] L.F. Wang, H.Y. Hu, "Flexural wave propagation in single-walled carbon nanotubes," Physical Review B, Vol. 71, no. 19, p.195412.2005.

[10] Q. Wang, Q, Varadan, V.K., Quek, S.T., "Small scale effect on elastic buckling of carbon nanotubes with nonlocal continuum models», Physics Letters. A, vol.357, no.2, pp. 130-135., 2006.

[11] J. Bocko, P. Lengvarský, "Vibration of Single-Walled Carbon Nanotubes by Using Nonlocal Theory", American Journal of Mechanical Engineering, Vol. 2, no. 7, pp.195-198, 2014.

[12] T. Natsuki, N. Matsuyama, Q.Ni, "Vibration analysis of carbon nanotube-based resonator using nonlocal elasticity theory", Applied Physics A, vol.120, no.4, pp.1309-1313, 2015. 
[13] A. Houmat, "Nonlinear free vibration of non-prismatic single-walled carbon nanotubes by a non-local shear deformable beam p-element", Acta Mechanica., vol 227. no.4, pp. 1051-1065, 2015.

[14] S. Govind, S. Bansal, "Design of Mass-sensor Based on Resonant Frequency Analysis of a Single Walled Nanotube", International Journal of Advanced Mechanical Engineering, vol.4, no.3, pp. 331342,2014.

[15] S.B. Coşkun, M.T. Atay, B. Öztürk, "Transverse Vibration Analysis of Euler-Bernoulli Beams Using Analytical Approximate Techniques", Advances in Vibration Analysis Research, Dr. Farzad Ebrahimi (Ed.), InTech.

[16] C.W. Bert, M. Malik, "Differential quadrature method in computational mechanics: A review", Applied Mechanics Review, vol. 49, no.1, pp. 1-27. 1996.

[17] W. Chen, A.G. Striz, C.W. Bert, "A new approach to the differential quadrature method for fourth-order equations", International Journal for Numerical Methods in Engineering, vol. 40, no.11, pp. 1941-1956. 1997.

[18] MATLAB and Statistics Toolbox Release 2012b, The MathWorks, Inc., Natick, Massachusetts, United States.
Publish your research article in AIJR journals-

$\checkmark$ Online Submission and Tracking

$\checkmark$ Peer-Reviewed

$\checkmark$ Rapid decision

$\checkmark \quad$ Immediate Publication after acceptance

$\checkmark$ Articles freely available online

$\checkmark \quad$ Retain full copyright of your article.

Submit your article at journals.aijr.in

Publish your books with AIJR publisher-

$\checkmark$ Publish with ISBN and DOI.

$\checkmark$ Publish Thesis/Dissertation as Monograph.

$\checkmark$ Publish Book Monograph.

$\checkmark$ Publish Edited Volume/ Book.

$\checkmark$ Publish Conference Proceedings

$\checkmark \quad$ Retain full copyright of your books.

Submit your manuscript at books. aijr.org 